\title{
В.В. ЛИТВИНЕНКО
}

\section{ДОСЛІДЖЕННЯ ХАРАКТЕРИСТИК СПРАЦЬОВУВАННЯ ІНДУКЦІЙНО-ДИНАМІЧНОГО МЕХАНІЗМУ}

Приведено конструкцію прямоходового індукційно-динамічного механізму, що застосовується в швидкодіючих брейкерах. Розроблено принципову електричну схему лабораторного стенду 3 дослідження індукційно-динамічного механізму та розглянуто принцип роботи схеми. Приведено опис елементів електричної схеми. Виготовлено макетний зразок індукційно-динамічного механізму та змонтовано мобільний лабораторний стенд з необхідними апаратами, закріпленими на DIN-рейці та допоміжними аксесуарами. Допоміжні деталі для монтажу елементів стенду виготовлені за допомогою сучасного 3D принтера FLASHFORGE CREATOR PRO. OTримано осцилограми перехідних процесів при спрацьовуванні індукційно-динамічного механізму, а саме: осцилограми струму в обмотці механізму та напруги на накопичувальному конденсаторі та осцилограма переміщення рухомого диску. Лабораторний стенд використовується у навчальному процесі як складова лабораторного практикуму з дисципліни «Електричні апарати».

Ключові слова: індукційно-динамічний механізм, котушка, диск, накопичувальний конденсатор.

\section{В.В. ЛИТВИНЕНКО}

\section{ИССЛЕДОВАНИЕ ХАРАКТЕРИСТИК СРАБАТЫВАНИЯ ИНДУКЦИОННО-ДИНАМИЧЕСКОГО МЕХАНИЗМА}

Приведена конструкция прямоходового индукционно-динамического механизма, применяемого в быстродействующих брэйкерах. Разработана принципиальная электрическая схема лабораторного стенда по исследованию индукционно-динамического механизма и рассмотрен принцип работы схемы. Приведено описание элементов электрической схемы. Изготовлен макетный образец индукционнодинамического механизма и смонтирован мобильный лабораторный стенд с необходимыми аппаратами, закрепленными на DIN-рейке и вспомогательными аксессуарами. Вспомогательные детали для монтажа элементов стенда изготовлены с помощью современного 3D принтера FLASHFORGE CREATOR PRO. Получены осциллограммы переходных процессов при срабатывании индукционнодинамического механизма, а именно: осциллограммы тока в обмотке механизма и напряжения на накопительном конденсаторе и осциллограмма перемещения подвижного диска. Лабораторный стенд используется в учебном процессе как составляющая лабораторного практикума по дисциплине «Электрические аппараты».

Ключевые слова: индукционно-динамический механизм, катушка, диск, накопительный конденсатор.

\section{V.V. LYTVYNENKO}

\section{RESEARCH OF THE INDUCTION-DYNAMIC MECHANISM OPERATION CHARACTERISTICS}

The design of the linear-drive induction-dynamic mechanism used in high-speed breakers is presented. The research mechanism consists of a coil with leads and a moving disk. The coil of the mechanism is wound with copper tape, the disk is made of copper bus and mounted on the rod, which passes through the hole of the coil. A circuit diagram of a laboratory test bench for the study of the induction-dynamic mechanism has been developed and the principle of operation of the circuit has been considered. A description of the electrical circuit elements is given. A prototype model of the induction-dynamic mechanism was manufactured and a mobile laboratory stand was assembled with the necessary devices mounted on a DIN-rail and ancillary accessories. The high speed of the induction-dynamic mechanism is ensured by the presence of a storage capacitor, which discharges the stored energy to the mechanism coil in a relatively short time. Auxiliary parts for mounting the elements of the stand are made using a modern 3D printer FLASHFORGE CREATOR PRO. Oscillograms of transients are obtained when an induction-dynamic mechanism is triggered, namely: oscillograms of current in the mechanism winding and of voltage on a storage capacitor as well as oscillogram of moving disk displacement. The laboratory stand is used in the educational process as a component of the laboratory workshop on the discipline "Electrical Apparatus"

Keywords: induction-dynamic mechanism, coil, disk, storage capacitor.

Вступ. Сьогодні в енергетичних установках середньої напруги в якості комутаційних пристроїв широке поширення набули вакуумні брейкери (circuitbreaker) завдяки цілому ряду переваг: невибагливість в експлуатації, невеликі розміри, малий хід контактів, ефективність гасіння електричної дуги тощо [1]. Захист електромереж від коротких замикань визначається стабільністю характеристик та мінімальним часом спрацьовування апаратів захисту. В якості актуаторів в брейкерах застосовуються як пружинномоторні з механічною защіпкою, так і електромагнітні актуатори різних конструкцій з механічною защіпкою [2]. Застосування індукційно-динамічних механізмів (ІДМ) в якості швидкодіючих актуаторів в електричних апаратах обумовлено простотою i надійністю конструкції цих пристроїв та їх високою швидкодією. ІДМ відносяться до електромеханічних перетворювачів індукційного типу, які широко застосовуються для створення потужних силових імпульсів, що впливають на різні матеріальні об'єкти [3]. В цих перетворювачах при збудженні нерухомого індуктора від ємнісного накопичувача енергії в близько розташованому електропровідному якорі індукується струм, взаємодія якого з магнітним полем індуктора створює електродинамічну силу, відштовхуючу якір від індуктора. Завдяки швидкодії та простоті конструкції ІДМ може бути застосовано як пристрій для висмикування защіпки актуатора високовольтного брейкеру та зменшення часу спрацьовування апарату при відключенні аварійних струмів.

Мета роботи - розробка електричної схеми та виготовлення макетного зразку для дослідження характеристик спрацьовування індукційно-динамічного механізму.

Конструкція індукційно-динамічного механізму. Одним 3 найбільш поширених типів ІДМ $\epsilon$ конструкції без магнітної системи $з$ диском в якості рухомого елементу приведена на рис. 1. Їх основна 
перевага в тому, що рухливий елемент 2 (диск) не пов'язаний з котушкою-індуктором 1. У зв'язку з цим механічна зносостійкість індукційно-динамічних механізмів може бути досить високою. Джерелом енергії ІДМ служить, як правило, накопичувальний конденсатор.

Прямоходова конструкція ІДМ застосовується в швидкодіючих брейкерах в якості розчеплювачів [4].

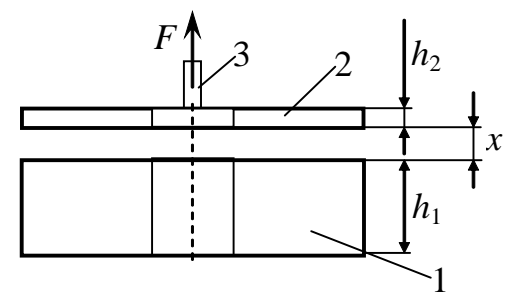

Рис. 1. Прямоходова конструкція ІДП

Обмотка 1 намотана або стрічкою, або прямокутним проводом в один або кілька шарів. Виводи обмотки приєднуються до накопичувального конденсатора через тиристорний ключ, що забезпечує в котушці напівсинусоїдальний імпульс струму.

Для підвищення ефективності схеми живлення котушки, можливі варіанти схемного рішення тиристорного ключа: з зустрічно-паралельним діодом, при цьому в котушці відбувається коливальний затухаючий процес зміни струму, або з шунтувальним котушку діодом, в цьому випадку має місце аперіодичне згасання струму. Один тиристор практично не застосовується через неекономічність (неповний розряд конденсатора). Якір 2 виконується в формі диска 3 струмопровідного матеріалу. Якір пов'язаний зі штоком 3 та передає зусилля на контактну систему або защіпку пружинного приводу.

Індукційно-динамічна взаємодія використовується також в індукційно-динамічних двигунах (ІДД) [5]. ІДД застосовуються для створення потужних силових імпульсів при вирішенні різноманітних технічних завдань вібраційного впливу, деформації та перфорації оброблюваних поверхонь і об'єктів.

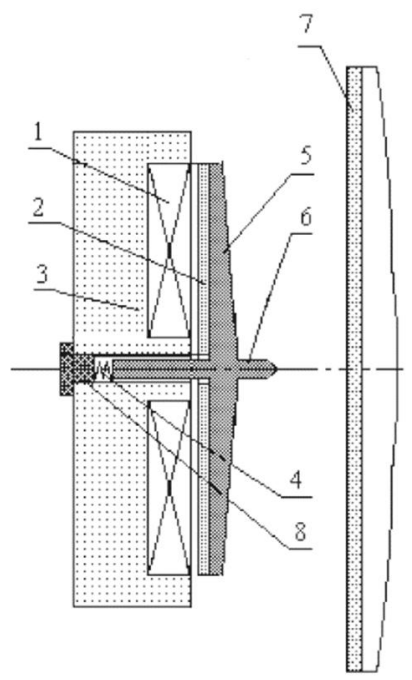

Рис. 2. Конструкція ІДД

ІДД дискової конфігурації складається з індуктора 1 , укладеного в діелектричний корпус 3 , і електропро- відного якоря 2, прикріпленого до ударного елементу 5 3 бойком 6, спрямованим в бік поверхні 7 деформованого об'єкта. Пружина 4, яка притискає якір до індуктора і повертає його в початкове положення після завершення удару, кріпиться на патроні 8 (рис. 2).

Індукційно-динамічний актуатор в апаратах захисту працює у перехідному, динамічному режимі, тому доцільним $є$ дослідження саме перехідних характеристик спрацьовування ІДМ.

Лабораторний стенд для дослідження ІДМ. Принципова електрична схема лабораторного стенду 3 дослідження ІДМ наведена на рис. 3.

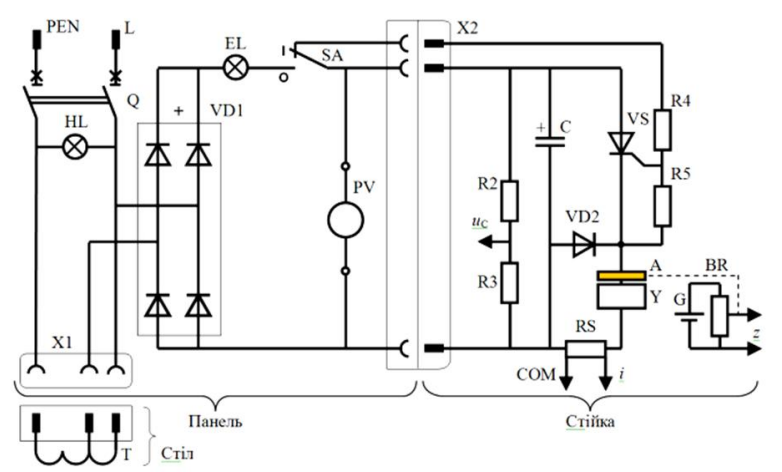

Рис. 3. Принципова електрична схема

В електричній схемі застосовано такі позначення: T - автотрансформатор; HL - сигнальна лампа підключення стенду до мережі живлення; EL - лампа розжарювання для сигналізації закінчення процесу заряду конденсатора; VD1 - діодний міст; VD2 силовий діод; VS - тиристор; Q - вимикач в колі змінного струму на вході макетного зразка; С конденсатор; PV - вольтметр, який показує рівень заряда конденсатора (напругу на конденсаторі C); SA - перемикач; RS - шунт для під’єднання осцилографа; R2 - резистор на 510 кОм; R3 - резистор на 56 кОм; R4 - резистор на 1 кОм; R5 - резистор на 10 кОм; G гальванічний елемент; A - рухомий диск IДМ; Y електромагніт; BR - резистивний датчик.

Висока швидкодія ІДМ забезпечується наявністю накопичувального конденсатора, який розряджає запасену енергію на котушку механізму за достатньо короткий час.

Сигнал для вимірювання напруги на конденсаторі подається 3 подільника напруги, утвореного резисторами R2-R3 (1:10).

При замиканні ввідного автоматичного вимикача Q загорається сигнальна лампа HL i на вхід автотрансформатора Т поступає змінна напруга 220 B.

PEN провідник та движок автотрансформатора T підключені до входу діодного моста VD1. Таким чином можна регулювати напругу на вході діодного моста VD1 в широких межах. Діодний міст VD1 необхідний для перетворення змінної напруги мережі у випростану напругу.

У вихідному положенні перемикач SA повинен знаходитися в положенні I. При цьому конденсатор C буде розряджений через резистори R4-R5, обмотку ІДМ та шунт.

Якщо перемикач SA перевести в положення О, 
то перетворена в діодному мосту змінна напруга потрапляє на конденсатор С, який починає заряджатися через лампу EL. Лампа EL в цьому випадку виконує функцію обмежуючого резистора. Заряд конденсатора С відбувається за експоненціальним законом і вольтметр PV показує плавне зростання напруги на конденсаторі. Лампа EL згасає, коли процес заряду конденсатора повністю закінчиться.

Тиристор VS є замкненим зважаючи на відсутність струму управління на його електроді управління. Якщо перемикач SA перевести в положення I 3'явиться струм управління в колі тиристора VS. Відмикаючий постійний струм управління тиристора Т25 дорівнює 150 мА, на електрод управління тиристора потрапляє струм приблизно 300 мА, що є більшим, ніж відмикаючий струм управління. Так як на аноді з'являється позитивний потенціал, відносно катоду, тиристор VS відкривається. В результаті відкриття тиристора VS до обмотки ІДМ прикладається практично повна напруга конденсатора C (за винятком падіння напруги на тиристорі $\approx 1$ В), 335 В. Через обмотку ІДМ протікає імпульсний струм. Імпульсний струм створює в обмотці змінне магнітне поле, яке пронизує мідний диск. В результаті цього в диску наводиться електрорушійна сила (ЕРС) та виникає струм протилежний за напрямом струму в обмотці. Взаємодія двох різноспрямованих струмів створює силу, що відкидає мідний диск від нерухомої обмотки і струм починає зменшуватись від свого максимального значення. Отже і напруга на конденсаторі С зменшується.

Поки напруга на конденсаторі C більше 0 діод VD2 замкнений, тому що на його катоді позитивний потенціал. В момент, коли напруга на конденсаторі досягне 0 та спрямується до зменшення у від'ємному напрямку діод VD2 відкриється. Струм обмотки почне протікати в замкненому контурі: обмотка ІДМ - шунт RS - діод VD2. Струм у тиристорі переривається, оскільки керуючий струм відсутній i напруга на тиристорі дорівнює 0. Отже тиристор закривається. Струм в обмотці ІДМ плавно зменшується до 0. Розроблена схема дає можливість дослідним шляхом зняти перехідні характеристики спрацьовування ІДМ, а саме: отримати осцилограму струму в обмотці, напруги на накопичувальному конденсаторі та за допомогою застосування прецизійного потенціометричного датчика осцилограму переміщення диску механізму.

Основною дослідною частиною лабораторного стенду є ІДМ, який складається 3 котушки з виводами та рухомого диску. Котушка ІДМ має 75 витків, намотаних мідною стрічкою $30 \times 0,1$ мм.

Диск виконано 3 мідної шини, товщиною 2 мм і закріплено на рухомому штоку, який проходить крізь отвір котушки.

В конструкції лабораторного стенду шток ІДМ механічно пов'язаний з движком прецизійного потенціометричного датчика MEGATRON-MUNCHEN, сигнал на виході якого пропорційний переміщенню движка датчика. В реальних конструкціях апаратів шток механічно пов'язаний 3 контактною системою та при спрацьовуванні ІДМ розмикає контакти апарата. Креслення лабораторної установки приведено на рис. 4.

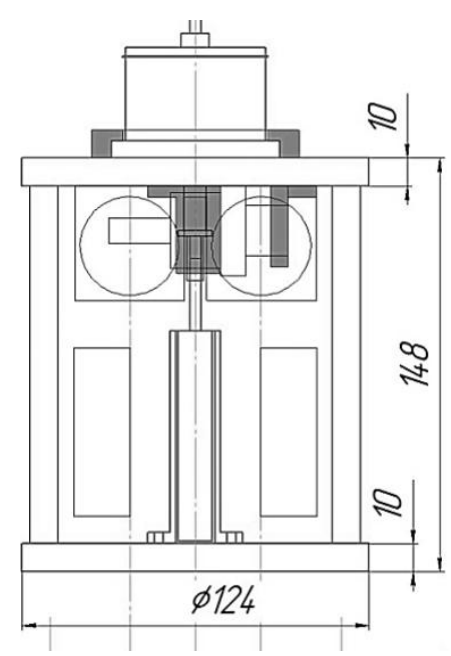

Рис. 4. Креслення установки

Макетний зразок установки представлено на рис. 5.

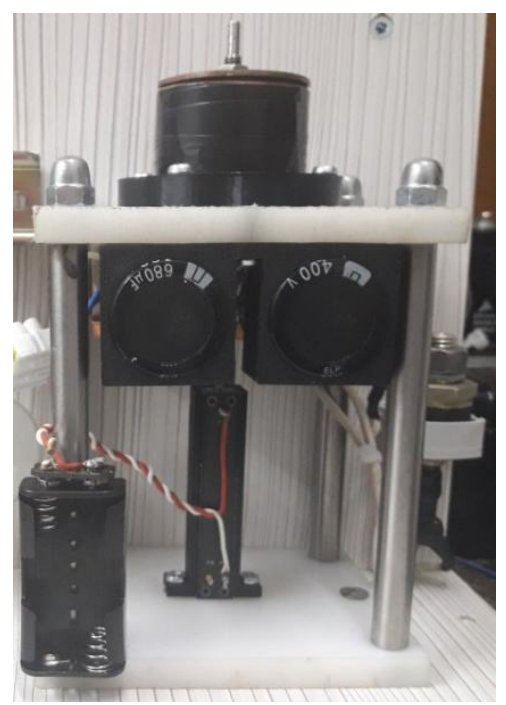

Рис. 5. Макетний зразок установки

Усі апарати та допоміжні аксесуари, які монтуються на DIN-рейці у лабораторному стенді кріпляться на дерев'яній основі. На вводі дослідного стенду встановлений двохполюсний автоматичний вимикач Q. Для того, щоб перетворити змінну напругу у випростану пульсуючу в дослідній схемі використовується діодний міст. Накопичувальний конденсатор, який розряджається на котушку індукційно-динамічного механізму представляє собою два електролітичних конденсатор (680 мкФ; $400 \mathrm{~B} ; 105{ }^{\circ} \mathrm{C}$ ) в алюмінісвому циліндричному корпусі, 3 односпрямованим дротяними гнучкими виводами радіального типу (radial lead), які з'єднані паралельно. Призначення силового діоду VD2 створення ланцюга, в якому розсіюється енергія, накопичена в котушці індуктивності ІДМ, після розряду на неї накопичувального конденсатора. Монтаж основних елементів лабораторного стенду проводився за допомогою допоміжних деталей, які 
були виготовлені на сучасному 3D принтері FLASHFORGE CREATOR PRO на кафедрі «Електричні апарати».

Характеристики спрацьовування ІДМ. Зняття необхідних осцилограм при дослідженні ІДМ було зроблено за допомогою сучасного двоканального цифрового осцилографу Siglent SDS1022DL. Після розряду накопичувального конденсатора на обмотку ІДМ отримано осцилограми імпульсу струму що протікає в обмотці та напруги на конденсаторі (рис. 6). Згідно $з$ осцилограмою максимальне значення струму $650 \mathrm{~A}$.

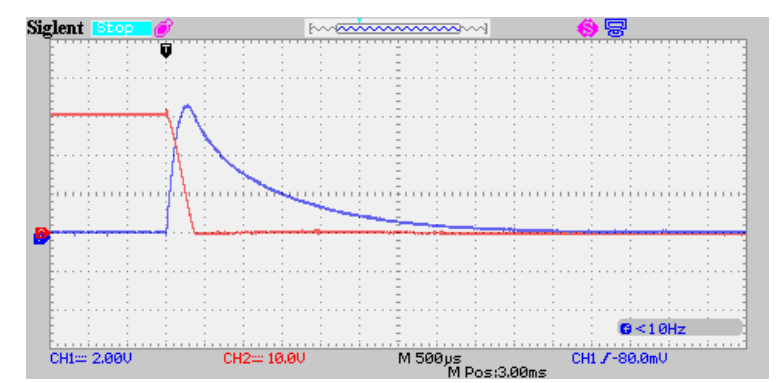

Рис. 6. Осцилограми струму в обмотці ІДМ та напруги на накопичувальному конденсаторі

Для отримання осцилограми переміщення мідного диску ІДМ, осцилограф підключається до виводів прецизійного потенціометричного датчика BR (рис. 3), сигнал на виході якого пропорційний переміщенню движка датчика, механічно пов'язаного зі штоком, що проходить крізь отвір в котушці ІДМ і до якого кріпиться рухомий мідний диск механізму. В результаті проведення досліду було отримано осцилограму (рис. 7).

У розробленому макетному зразку ІДМ максимальний хід якоря обмежений довжиною штока та движка датчика і складає 18 мм.

Розроблений ІДМ підлягає математичному моделюванню та потребує проведення подальших досліджень 3 ціллю оптимізації конструкції та покращення характеристик.

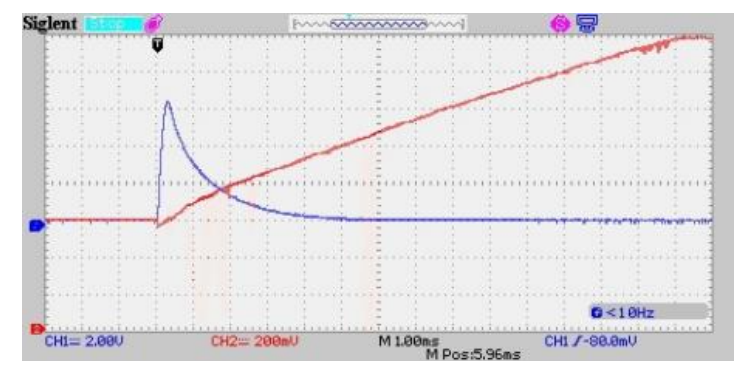

Рис. 7. Осцилограми струму в обмотці ІДМ та переміщення диску
Розрахунок ІДМ є досить складним завданням, бо повинен враховувати процеси, що відбуваються в електричному ланцюзі, механічній системі і електромагнітному полі.

Висновки. 1. Розроблено принципову електричну схему лабораторного стенду 3 дослідження ІДМ та розглянуто принцип роботи схеми.

2. Розроблено та виготовлено макетний зразок лабораторного стенду з дослідження ІДМ.

3. Отримано осцилограми перехідних процесів при спрацьовуванні ІДМ.

4. Лабораторний стенд 3 дослідження ІДМ використовується у навчальному процесі як складова лабораторного практикуму з дисципліни «Електричні апарати».

\section{Список літератури}

1. Клименко Б.В. Електричні апарати. Електромеханічна апаратура комутації, керування та захисту. Загальний курс: навчальний посібник. - Харків: Вид-во «Точка», 2012. - 340 с.

2. Клименко Б.В., Бугайчук В.М., Гречко А.М. Электромагнитные приводы вакуумных выключателей средних напряжений // Вестник НТУ "ХПИ". - 2004. - No 42. - С.73-80.

3. Болюх В.Ф., Марков А.М., Лучук В.Ф., Рассоха М.А., Щукин И.С. Экспериментальные и теоретические исследования ударного электромеханического преобразователя индукционного типа с различными индукторами // Електротехніка i Електромеханіка. 2009. №5.

4. Электрические и электронные аппараты: Учебник для вузов. / Под ред. Ю.К. Розанова. - М.: Информэлектро, 2001 - 420 с.

5. Болюх В.Ф., Рассоха М.А., Щукин И.С. Применение импульсной модуляции для повышения эффективности индукционнодинамического двигателя

\section{References (transliterated)}

1. Klymenko B.V. Elektrychni aparaty. Elektromekhanichna aparatura komutatsii, keruvannia ta zakhystu. Zahalnyi kurs: navchalnyi posibnyk. Kharkiv: Vyd-vo «Tochka», 2012.340 p.

2. Klimenko B.V., Bugajchuk V.M., Grechko A.M. Elektromagnitnye privody vakuumnyh vyklyuchatelej srednih napryazhenij//Vestnik NTU "HPI".-2004.-No 42.- s.73-80.

3. Bolyuh V.F., Markov A.M., Luchuk V.F., Rassoha M.A., Shchukin I.S. Eksperimental'nye i teoreticheskie issledovaniya udarnogo ehlektromekhanicheskogo preobrazovatelya indukcionnogo tipa $\mathrm{s}$ razlichnymi induktorami// Elektrotekhnika i Elektromekhanika. 2009. №5.

4. Elektricheskie i elektronnye apparaty: Uchebnik dlya vuzov. / Pod red. YU.K. Rozanova. - M.: Informelektro, 2001. - $420 \mathrm{~s}$.

5. Bolyuh V.F., Rassoha M.A., Shchukin I.S. Primenenie impul'snoj modulyacii dlya povysheniya ehffektivnosti indukcionnodinamicheskogo dvigatelya.

\section{Відомості про авторів / Сведения об авторах /About the Authors}

Литвиненко Вікторія Володимирівна (Литвиненко Виктория Владимировна, Lytvyпеnko Victoriia Vladimirovna) - Національний технічний університет "Харківський політехнічний інститут", старший викладач кафедри електричні апарати, м. Харків, Україна; e-mail: vikalitv21082@gmail.com 